Vol 10, Issue 11, 2017

\title{
ACCUMULATIVE REPETITIVE STRAIN INJURY AMONG BUSINESS PROCESS OUTSOURCING EMPLOYEES: A SURVEY STUDY
}

\author{
DHEERAJ LAMBA ${ }^{1 *}$, RITAMBHARA K UPADHYAY ${ }^{2}$
}

${ }^{1}$ Department of Physiotherapy, Lovely Professional University, Phagwara, Punjab, India. ${ }^{2}$ Division of Academic Affairs, Lovely Professional University, Phagwara, Punjab, India. Email: dheeraj.20191@lpu.co.in

Received: 27 April 2017, Revised and Accepted: 17 July 2017

\section{ABSTRACT}

Objective: Computer overuse syndrome or repetitive strain injury is the most common problem among the people in all age groups. Several studies have found the adverse effect of using computers for a long duration. In the modern tech-savvy world, usage of computers is something unavoidable. The objective of this survey study is to find out the accumulative repetitive strain injury among the business process outsourcing employees.

Methods: This study was conducted in different business process outsourcings in Noida, and a convenient sampling method was used to collect data through Neck Pain Disability Index (NPDI) and disabilities of the arm, shoulder and hand (DASH) questionnaire. The study comprised of total 230 subjects.

Results: The mean and standard deviation (SD) of NPDI score was found to be 32.12 and 11.26, respectively, whereas the mean and SD for DASH score was 24.34 and 7.44, respectively. The Chi-square value for NPDI and DASH was found to be 263.043 and 139.461 . The study shows that upper extremity pain is a common problem in employees working in the IT sector. The employees showed high rates of computer use-associated with upper extremity musculoskeletal symptoms and symptom-related functional limitation.

Conclusion: The findings of the study suggest a need to begin to evaluate interventions and to reduce the risks of developing computer overuse syndrome such as developing upper extremity symptoms, disability, and disorders among employees working in the IT sector who use computers for more than $40 \mathrm{hrs} /$ week. Intervention to reduce symptoms should include effective training in work rest patterns, good-working postures coupled with availability of appropriate equipment.

Keywords: Repetitive strain injury, Computer overuse syndrome, Business process outsourcing, Neck pain disability index, Disabilities of the arm; shoulder and hand.

(C) 2017 The Authors. Published by Innovare Academic Sciences Pvt Ltd. This is an open access article under the CC BY license (http://creativecommons. org/licenses/by/4. 0/) DOI: http://dx.doi.org/10.22159/ajpcr.2017.v10i11.19423

\section{INTRODUCTION}

In this tech-savvy era, computers are inevitable things. People who perform intensive work are at risk of developing pain and musculoskeletal disorders (MSDs) at the wrist, forearm, and neck [1]. The workplace risk factors involve a number of hours per week a person makes use of the computer, working in non-neutral body postures (e.g., looking up at the computer monitor and reaching for mouse), gender, increasing age, etc. [2-4]. With the increasing use of the computers in daily life and for work purposes, people are at the increased risk of developing MSDs. A survey conducted by the Harvard University reported that over half of the students experienced symptoms of computer overuse and nearly 13\% experienced the syndrome on using computers for an hour or less $[5,6]$. The risk factors involved that there were the use of computer for academic concentration purposes with students using computer for more than $20 \mathrm{hrs} /$ week and of course gender. Till date, no studies have been found to have been conducted to find the prevalence of computer overuse syndrome for repetitive strain injury among business process outsourcing (BPO) employees.

\section{METHODS}

1. Source of data: All subjects were recruited from different IT companies in Noida

2. Method of collection of data: Study design and survey study

3. Sampling: Convenient sampling technique used in this study

4. Sample size: Disabilities of the arm, shoulder and hand (DASH) and Neck Pain Disability Index (NPDI) questionnaire were distributed to total to 250 employees

5. Distribution of data was based on the inclusion and exclusion criteria.
Inclusion criteria

1. Gender: Both male and female subjects participated

2. Using computer more than $40 \mathrm{hrs} /$ week (approximately, 5-6 hrs/ day)

3. Communicating English and Hindi language.

Exclusion criteria

1. Any history of any upper limb fracture

2. Any history of pathological disorder of upper limb

3. All regular exercise

4. Congenital anomalies deficiency

5. Uncooperative.

Variables

1. Dependent variables: Neck Disability Index, DASH

2. Dependent variables: Age, gender using computer more than $40 \mathrm{hrs} /$ week.

\section{Outcome measures}

1. DASH

2. Neck Disability Index.

A total of 250 employees were selected from different IT companies in Noida. Convenient sampling techniques were used in this study. The entire employees attending on the day were provided with the DASH and NPDI questionnaire and the consent form. Only those employees were selected who were fit into the inclusion criteria by asking some questions such as how long they work on computers, whether they 
have any pathological disorder of upper limb, whether they do exercise regularly or not. NPDI questionnaire contained 10 questions about neck pain such as pain intensity and how much their neck pain had affected their ability to manage their everyday activities, i.e., personal care reading, lifting, headache, work, concentration, driving, work, sleep, and recreation. The instrument scored out of 45 (50) converted to $100 \%$ and then divided into two. Two missed items should be admissible. With three or more missing items, the administration should be regarded as unacceptable.

The DASH questionnaire contained 30 questions that were designed to measure the physical disability and symptoms in heterogeneous population that included both males and females. At least, 27 out of 30 questions must be completed to be eligible to be included in the study. 250 questionnaires were distributed. Out of 250 questionnaires, 230 were included and 20 were excluded from the study. The score was calculated according to the number of questions filled by the employees and then converted into percentage.

The purpose of the questionnaire was to identify the employees in IT sector who were suffering from upper extremity pain/disorder.

\section{RESULTS}

Statistics were performed using SPSS version 20. Result was calculated with 0.05 level of accuracy.

\section{DISCUSSION}

Musculoskeletal upper extremity symptoms and complaints of shoulder, neck and arms are common in the general population and computer users in many industrialized countries $[7,8]$. In recent years, when it

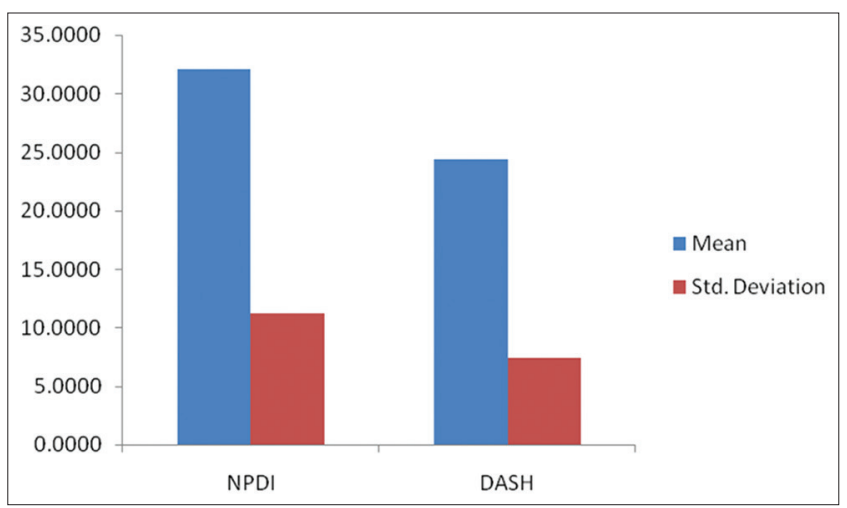

Fig. 1: Mean and standard deviation of Neck Pain Disability Index and disabilities of the arm, shoulder and hand score for subjects included in the study

Table 1: Chi-square test between NPDI and DASH score for subjects included in the study

\begin{tabular}{lcll}
\hline Variables & N & Chi-square value & p value \\
\hline NPDI versus DASH score & 230 & 3375.648 & $<0.05$ \\
\hline $\begin{array}{l}\text { DASH: Disabilities of the arm, shoulder and hand, NPDI: Neck Pain Disability } \\
\text { Index }\end{array}$
\end{tabular}

Table 2: Correlation between of NPDI and DASH score for subjects included in the study

\begin{tabular}{llll}
\hline Variables & $\mathbf{N}$ & r value & p value \\
\hline NPDI versus DASH score & 230 & 0.631 & $<0.05$ \\
\hline $\begin{array}{l}\text { DASH: Disabilities of the arm, shoulder and hand, NPDI: Neck Pain Disability } \\
\text { Index }\end{array}$
\end{tabular}

comes to computer-related office work, it has intensified in developed countries and to overcome the shortage of workforce; these developed countries outsource their work to underdeveloped or developing countries as they get cheap labor there. The 2004 census revealed that computer-related work in Germany constituted a large part of the daily working routine for approximately 21 million people $55 \%$ of those with paid work) [8]. The etiology of neck, shoulder and forearm/hands complaints in computer workers is still not completely understood. Several risk factors related to different physical exposures at work and psychological conditions have been identified as potential causes for neck, shoulder and forearm/hands complaint. These exposures can be physical exposures related to static neck and arm postures, workplace design, repetitive tasks $[1,9]$ and also psychosocial factors related to

Table 3: Mean and SD of NDPI and DASH for the subjects included in the study

\begin{tabular}{lllll}
\hline \multicolumn{4}{l}{ Descriptive statistics } \\
\hline Variables & N & Minimum & Maximum & Mean \pm SD \\
\hline NPDI & 230 & 20.00 & 62.00 & $32.1235 \pm 11.25918$ \\
DASH & 230 & 9.15 & 47.10 & $24.3400 \pm 7.44057$ \\
Valid N & 230 & & & \\
(listwise) & & & & \\
\hline
\end{tabular}

SD: Standard deviation, DASH: Disabilities of the arm, shoulder and hand, NPDI: Neck Pain Disability Index

\begin{tabular}{ll}
\hline Test statistics & \\
\hline Variables & NPDI \\
\hline Chi-square & $263.043^{\text {a }}$ \\
df & 27 \\
Asymptotic significance & 0.000
\end{tabular}

${ }^{\mathrm{a}} 0$ cells $(0.0 \%)$ have expected frequencies $<5$. The minimum expected cell frequency is 8.2. NPDI: Neck Pain Disability Index

\begin{tabular}{ll}
\hline Test statistics & \\
\hline Variables & DASH \\
\hline Chi-square & $139.461^{\mathrm{a}}$ \\
$\mathrm{df}$ & 112 \\
Asymptotic significance & 040 \\
\hline a113 cells (100.0\%) have expected frequencies $<5$. The minimum expected cell \\
frequency is 2.0. DASH: DASH: Disabilities of the arm, shoulder and hand
\end{tabular}

Table 4: Frequency distribution of NPDI

\begin{tabular}{lll}
\hline Row labels & Count of NPDI & Percentage \\
\hline $20-30$ & 120 & 52.17 \\
$30-40$ & 46 & 20 \\
$40-50$ & 40 & 17.39 \\
$50-60$ & 21 & 9.13 \\
$60-70$ & 3 & 1.3 \\
Grand total & 230 & \\
\hline
\end{tabular}

NPDI: Neck Pain Disability Index

Table 5: Frequency distribution for DASH score

\begin{tabular}{lll}
\hline Row labels & Count of DASH & Percentage \\
\hline$<0$ or (blank) & 1 & \\
$0-10$ & 54 & 0.44 \\
$10-20$ & 126 & 23.47 \\
$20-30$ & 38 & 54.78 \\
$30-40$ & 11 & 16.52 \\
$40-50$ & 230 & 4.78 \\
Grand total & \\
\hline
\end{tabular}

DASH: Disabilities of the arm, shoulder and hand 


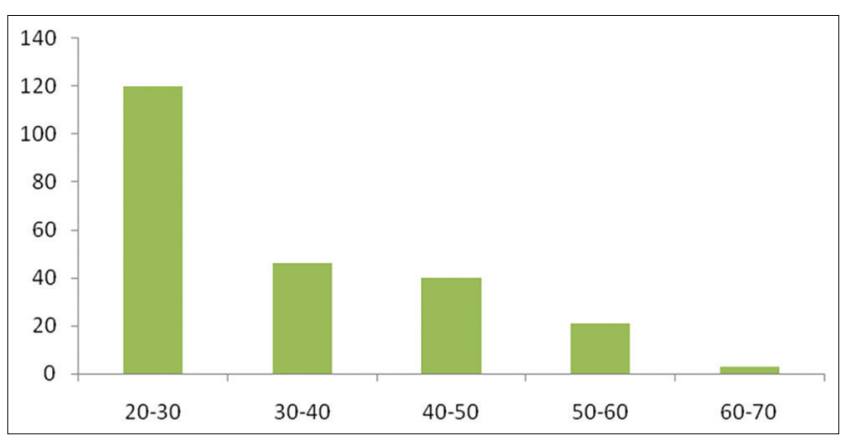

Fig. 2: Frequency distribution of Neck Pain Disability Index

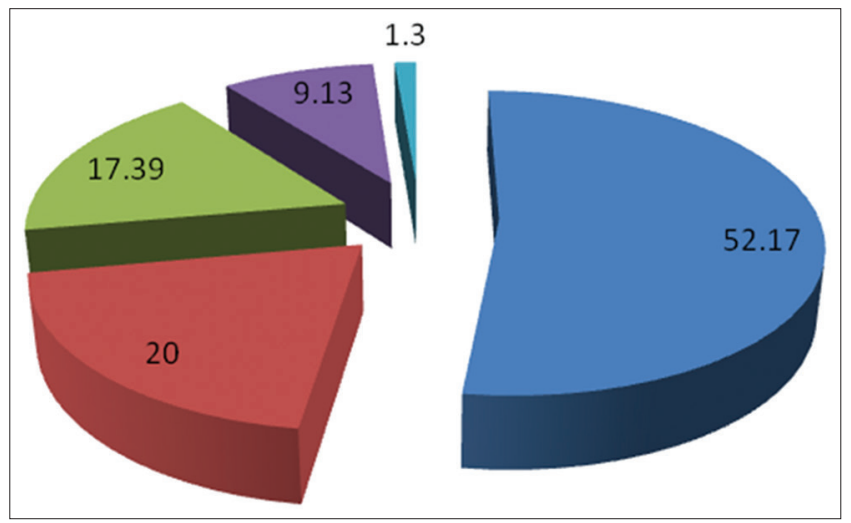

Fig. 3: Frequency distribution of Neck Pain Disability Index

job characteristics, having little influence on one's work situation, high quantitative job demands and limited support from coworkers or supervisors $[10,11]$. Fewer studies have been found to have investigated the interaction between ergonomic/psychical and psychosocial factors, for instance, the concept of work style $[12,13]$.

Furthermore, individual factors (e.g., previous symptoms and age) have also been discussed in the literature as potential risk factors for complaints. Hence, an etiological model explaining shoulder and neck and forearm complaints should consist of both psychosocial and physical factors at work [14]. Monitor software then directly measures computer input device activities (pointing device and keyboard activities). Computer usage monitor software is an unobtrusive and accurate exposure assessment tool [15] and it does not require the high cost or work associated with traditional direct measurement methods [16]. Furthermore, with the longitudinal and continuous data collected by computer usage monitor software, exposure within short windows can be accurately calculated to examine the shortterm dose-response relation between computer usage and MSDs. In addition to computer usage duration, gender has also been associated with MSD prevalence, e.g., computer-related upper extremity MSDs is more prevalent among females $[1,5,17]$. While gender differences could diminish when physical exposures are controlled [17], laboratory studies consistently demonstrate gender differences in physical exposure to posture and force load [18-22]. Exposure duration of computer usage can be objectively quantified by computer usage.

The study was aimed at finding the prevalence of computer overuse syndrome among BPO employees. This study comprised of 230 subjects, who were recruited for the survey. The first study investigated the prevalence of computer overuse syndrome among BPO employees in Noida city. The diagnosis was made by NPDI and DASH questionnaire. The reliability of the DASH was excellent with intraclass correlation coefficient of 0.97 . The test-retest reliability was moderate for the NPDI with intraclass correlation coefficient of 0.68 (Tables 1 and 2).

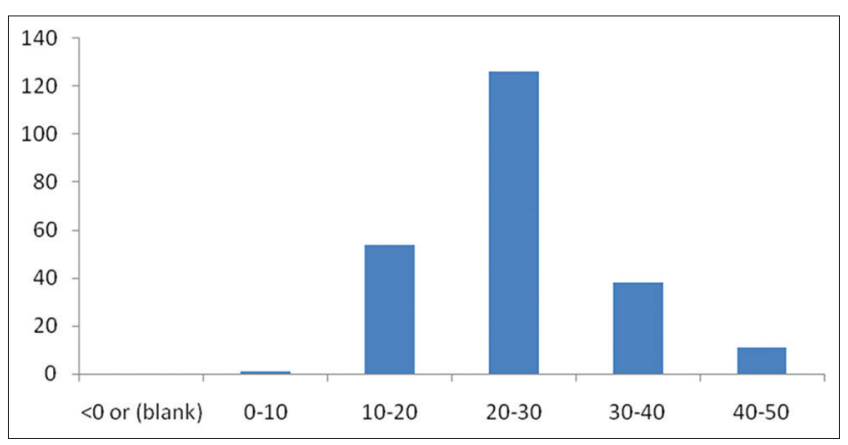

Fig. 4: Frequency distribution for disabilities of the arm, shoulder and hand score

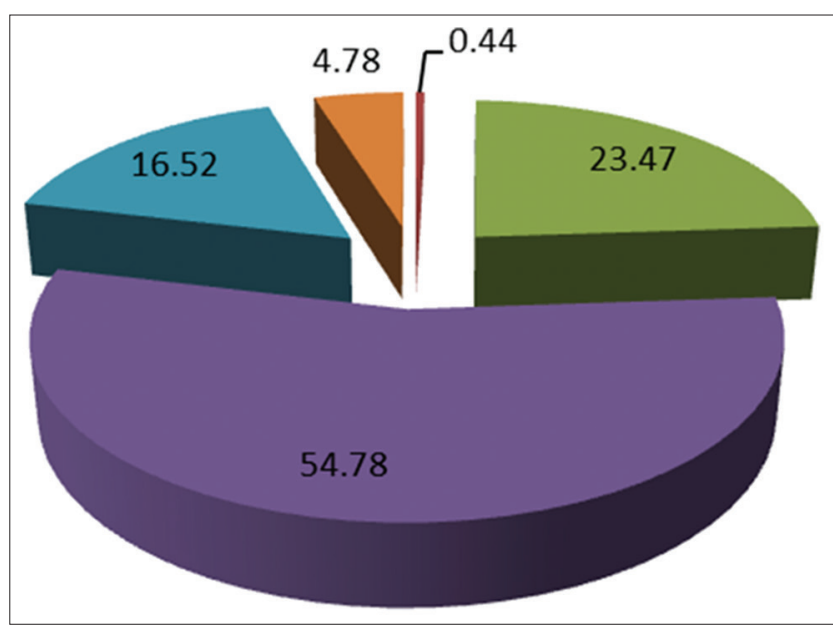

Fig. 5: Frequency distribution for disabilities of the arm, shoulder and hand score

The increased usage of computer screen, keyboard and mouse in the recent years has resulted in increased prevalence of upper extremity pain. Poor workstation design, continuous computer usage for more than 55-60 hrs/week (approximately 7-8 hrs/day) as per their workplace demand has been associated with an increased risk of developing symptoms related to MSDs.

This study comprised 230 employees of IT companies with a response rate of $95 \%$. The mean value of the NPDI has been found to be 32.12 and the SD value to be 11.26 (Table 3 and Fig. 1). The mean value and standard deviation (SD) of DASH have been found to be 24.34 and 7.44, respectively.

The number of frequency distribution has been highest in the range 2030 for NPDI followed by 30-40, 40-50, and 50-60 (Table 4, Figs. 2 and 3). This shows that nearly $52.17 \%$ of employees of the IT sector were found to have computer overuse syndrome or repetitive strain injury. The frequency distribution for DASH has been found to be highest in the range of 20-30, followed by $10-20,30-40$ and $40-50$. This shows $54.78 \%$ of employees in IT sector have been found to have computer overuse syndrome (Table 5, Figs. 4 and 5).

This study was conducted for employees in IT sector who have prolonged working hours on the computer. The number of hours these employees have to work is fixed, but they can also work extra time to boost their salary and incentives. The finding of an increased risk for female gender is observed among computer users in the workplace and even among the students. A study conducted by the Harvard University too has reported the risk among students who used computer for long hours as per the demand of their course work and to excel in this competitive era. 


\section{CONCLUSION}

This study concludes that the employees showed high rates of computer-use associated upper extremity musculoskeletal symptoms and symptom-related functional limitation.

\section{REFERENCES}

1. Gerr F, Marcus M, Ensor C, Kleinbaum D, Cohen S, Edwards A, et al. A prospective study of computer users: I. Study design and incidence of musculoskeletal symptoms and disorders. Am J Ind Med 2002;41(1):221-35.

2. Punnet L, Berqvist U. Visual display unit work and upper extremity musculoskeletal disorders: A review of epidemiological findings. Vol. 16. Solna, Sweden: National Institute for Working Life - Ergonimic Expert Committee Document; 1997. p. 1-173.

3. Tittiranonda P, Burastero S, Rempel D. Risk factors for musculoskeletal disorders among computer users. Occup Med 1999;14(1):17-38, iii.

4. Marcus M, Gerr F, Monteilh C, Ortiz DJ, Gentry E, Cohen S, et al. A prospective study of computer users: II. Postural risk factors for musculoskeletal symptoms and disorders. Am J Ind Med 2002;41(4):236-49

5. Katz JN, Amick BC, Carroll BB, Hollis C, Fossel AH, Coley CM. Prevalence of upper extremity musculoskeletal disorders in college students. Am J Med 2000;109(7):586-8.

6. U.S. Department of Education. National Center for Education Statistics. Digest of Education Statistics, 2001. Washington, DC: Office of Educational Research and Improvement NCES; 2002. p. 1-597.

7. Gerr F, Marcus M, Monteilh C. Epidemiology of musculoskeletal disorders among computer users: Lesson learned from the role of posture and keyboard use. J Electromyogr Kinesiol 2004;14(1):25-31.

8. Klussmann A, Gebhardt H, Liebers F, Rieger MA. Musculoskeletal symptoms of the upper extremities and the neck: A cross-sectional study on prevalence and symptom-predicting factors at visual display terminal (VDT) workstations. BMC Musculoskelet Disord 2008;9:96.

9. Andersen JH, Harhoff M, Grimstrup S, Vilstrup I, Lassen CF, Brandt LP, et al. Computer mouse use predicts acute pain but not prolonged or chronic pain in the neck and shoulder. Occup Environ Med 2008;65(2):126-31.

10. Dellve L, Lagerström M, Hagberg M. Work-system risk factors for permanent work disability among home-care workers: A case-control study. Int Arch Occup Environ Health 2003;76(3):216-4.
11. van den Heuvel SG, van der Beek AJ, Blatter BM, Hoogendoorn WE, Bongers PM. Psychosocial work characteristics in relation to neck and upper limb symptoms. Pain 2005;114:47-53.

12. Feuerstein M, Nicholas RA, Huang GD, Haufler AJ, Pransky G, Robertson M. Workstyle: Development of a measure of response to work in those with upper extremity pain. J Occup Rehabil 2005;15(2):87-104.

13. Nicholas RA, Feuerstein M, Suchday S. Workstyle and upperextremity symptoms: A biobehavioral perspective. J Occup Environ Med 2005;47(4):352-61.

14. Bongers PM, Ijmker S, van den Heuvel S, Blatter BM. Epidemiology of work related neck and upper limb problems: Psychosocial and personal risk factors (part I) and effective interventions from a bio behavioural perspective (part II). J Occup Rehabil 2006;16(3):279-302.

15. Chang $\mathrm{CH}$, Wang JD, Luh JJ, Hwang YH. Development of a monitoring system for keyboard users' performance. Ergonomics 2004;47(14):1571-81.

16. Winkel J, Mathiassen SE. Assessment of physical work load in epidemiologic studies: Concepts, issues and operational considerations. Ergonomics 1994;37(6):979-88.

17. Punnett L, Bergqvist U. Musculoskeletal disorders in visual display unit work: Gender and work demands. Occup Med 1999;14(1):113-24, iv.

18. Martin BJ, Armstrong TJ, Foulke JA, Natarajan S, Klinenberg E, Serina E, et al. Keyboard reaction force and finger flexor electromyograms during computer keyboard work. Hum Factors 1996;38(4):654-64.

19. De Smet L, Ghyselen H, Lysens R. Incidence of overuse syndromes of the upper limb in young pianists and its correlation with hand size, hypermobility and playing habits. Chir Main 1998;17(4):309-13.

20. Karlqvist LK, Bernmark E, Ekenvall L, Hagberg M, Isaksson A, Rostö T. Computer mouse position as a determinant of posture, muscular load and perceived exertion. Scand J Work Environ Health 1998;24(1):62-73

21. Wahlström J, Svensson J, Hagberg M, Johnson PW. Differences between work methods and gender in computer mouse use. Scand J Work Environ Health 2000;26(5):390-7.

22. (a). Thakur S, Srivastava N. An update on neuropathic pain models, Int J Pharm Pharm Sci 2016;8(6):11-6. (b). Lua PL, Ibrahim UI. The application of communication technology in hospital and community pharmacies: A brief review. Int J Pharm Pharm Sci 2015;7(3):1-5. 